\title{
Protein Kinase Modulation of a Neuronal Cation Channel Requires Protein-Protein Interactions Mediated by an Src homology 3 Domain
}

\author{
Neil S. Magoski, ${ }^{1}$ Gisela F. Wilson, ${ }^{2}$ and Leonard K. Kaczmarek ${ }^{1}$ \\ ${ }^{1}$ Department of Pharmacology, Yale University, New Haven, Connecticut 06520, and ${ }^{2}$ Department of Biology, University \\ of Michigan, Ann Arbor, Michigan 48109
}

Accumulating evidence suggests that many ion channels reside within a multiprotein complex that contains kinases and other signaling molecules. The role of the adaptor proteins that physically link these complexes together for the purposes of ion channel modulation, however, has been little explored. Here, we examine the protein-protein interactions required for regulation of an Aplysia bag cell neuron cation channel by a closely associated protein kinase $C$ (PKC). In inside-out patches, the PKC-dependent enhancement of cation channel open probability could be prevented by the src homology 3 (SH3) domain, presumably by disrupting a link between the channel and the kinase. SH3 and PDZ domains from other proteins were ineffective. Modulation was also prevented by an SH3 motif pep- tide that preferentially binds the $\mathrm{SH} 3$ domain of src. Furthermore, whole-cell depolarizations elicited by cation channel activation were decreased by the src $\mathrm{SH} 3$ domain. These data suggest that the cation channel-PKC association may require $\mathrm{SH}$ domain-mediated interactions to bring about modulation, promote membrane depolarization, and initiate prolonged changes in bag cell neuron excitability. In general, protein-protein interactions between ion channels and protein kinases may be a prominent mechanism underlying neuromodulation.

Key words: Aplysia; bag cell neurons; cation channel; phosphorylation; protein kinase $\mathrm{C}$; protein-protein interaction; $\mathrm{SH} 3$ domain; excitability.
A fundamental mechanism underlying neuromodulation is the phosphorylation of ion channels by protein kinases (Levitan and Kaczmarek, 1997). In some cases, the ion channel and the kinase appear to be physically associated with one another (Holmes et al., 1996; Tsunoda et al., 1997; Yu et al., 1997; Tibbs et al., 1998; Davare et al., 2001), and this association can at times be robust enough to preserve kinase-dependent modulation either in cellfree patches (Bielefeldt and Jackson, 1994; Yu et al., 1997; Wilson et al., 1998) or after reconstitution into bilayers (Rehm et al., 1989; Chung et al., 1991). The colocalization and targeting of kinases to ion channels requires a means of orchestrating protein-protein interactions. The "signaling module" theory of protein-protein interaction proposes that association occurs through the binding of a larger section [(50-100 amino acids (aa)] of one protein, called a domain, to a smaller portion (5-10 aa) of a second protein, called a motif or binding peptide sequence (Cohen et al., 1995; Pawson, 1995; Pawson and Scott, 1997; Fanning and Anderson, 1999). A number of such domains have been implicated in ion channel function (for review, see Sheng and Wyszynski, 1997; Staub and Rotin, 1997). In the present work, we investigate the interactions between a cation channel, which is

Received March 29, 2001; revised Sept. 17, 2001; accepted Sept. 18, 2001.

This work was supported by Human Frontiers Science Program and Medical Research Council of Canada postdoctoral fellowships to N.S.M. and by National Institutes of Health operating grants to G.F.W. and L.K.K. We are very grateful to Dr. B. K. Kay for providing interaction domains and peptides, Dr. B. M. Olivera for providing lyophilized Conus textile venom, and N. M. Magoski for critical evaluation of earlier drafts of this manuscript.

Correspondence should be addressed to Dr. L. K. Kaczmarek, Department of Pharmacology, Yale University School of Medicine, 333 Cedar Street, New Haven, CT 06520. E-mail: leonard.kaczmarek@.yale.edu.

Copyright (ㄷ) 2001 Society for Neuroscience $0270-6474 / 01 / 210001-09 \$ 15.00 / 0$ responsible for prolonged changes in Aplysia bag cell neuron excitability, and a closely associated kinase.

The bag cell neurons of Aplysia californica control egg-laying behavior through a profound change in excitability, called the afterdischarge (Kupfermann, 1967; Kupfermann and Kandel, 1970; Pinsker and Dudek, 1977; Rothman et al., 1983; Conn and Kaczmarek, 1989). Stimulation of inputs to the bag cell neurons produces an $\sim 30$ min period of depolarization and action potential firing, followed by an $\sim 18 \mathrm{hr}$ refractory period during which another afterdischarge cannot be elicited. A pharmacological stimulus for initiating afterdischarges is Conus textile venom $(\mathrm{CtVm})$, which elicits a normal afterdischarge and refractory period (Wilson and Kaczmarek, 1993; Wilson et al., 1996; Magoski et al., 2000). CtVm activates a nonselective cation channel that provides a depolarizing drive for the afterdischarge and is key to controlling bag cell neuron excitability. The cation channel is regulated by several kinases and phosphatases, including a protein kinase $\mathrm{C}$ (PKC)-like enzyme that is colocalized with the cation channel in excised, inside-out patches (Wilson and Kaczmarek, 1993; Wilson et al., 1998). To determine whether the association between the kinase and the cation channel involves specific forms of protein-protein interactions, we have tested the ability of different interaction domains and motifs to interfere with the functional link between channel and kinase in excised, inside-out patches. We have also used whole-cell recording to introduce interaction domains into bag cell neurons and observe their effects on cation channel-induced depolarization. Our data indicate that the cation channel-kinase "association" requires src homology 3 (SH3) domain protein-protein interactions, and that disruption of this interaction prevents channel modulation and attenuates the long-lasting depolarization produced by cation channel activation. 


\section{MATERIALS AND METHODS}

Animals and cell culture. Adult $A$. californica weighing 100-200 gm were obtained from Marine Specimens Unlimited (San Francisco, CA) or Marinus Inc. (Long Beach, CA). Animals were housed in an 4001 aquarium containing continuously circulating, aerated Instant Ocean (Aquarium Systems, Mentor, $\mathrm{OH}$ ) salt water at $14^{\circ} \mathrm{C}$ on an $\sim 12 \mathrm{hr}$ light/dark cycle and were fed Romaine lettuce three times a week. All experiments were performed at room temperature $\left(18-20^{\circ} \mathrm{C}\right)$.

For primary cultures of isolated bag cell neurons, animals were anesthetized by an injection of isotonic $\mathrm{MgCl}_{2}(\sim 50 \%$ of body weight); the abdominal ganglion was removed and treated with neutral protease for $18 \mathrm{hr}$ at $18-20^{\circ} \mathrm{C}(13.33 \mathrm{mg} / \mathrm{ml} ; 165859$; Boehringer Mannheim, Indianapolis, IN) and dissolved in normal artificial seawater (nASW); the nASW was composed of (in mM): $460 \mathrm{NaCl}, 10.4 \mathrm{KCl}, 11 \mathrm{CaCl}_{2}, 55$ $\mathrm{MgCl}_{2}, 15 \mathrm{HEPES}, 1 \mathrm{mg} / \mathrm{ml}$ glucose, $100 \mathrm{U} / \mathrm{ml}$ penicillin, and $0.1 \mathrm{mg} / \mathrm{ml}$ streptomycin; $\mathrm{pH}$ adjusted to 7.8 with $\mathrm{NaOH}$. The ganglion was then transferred to fresh nASW, and the bag cell neuron clusters were dissected from their surrounding connective tissue. Using a fire-polished Pasteur pipette and gentle trituration, neurons were dispersed in nASW onto $35 \times 10 \mathrm{~mm}$ polystyrene tissue culture dishes (no. 25000; Corning, Corning, NY). Cultures were maintained in nASW for $1-3 \mathrm{~d}$ in a $14^{\circ} \mathrm{C}$ incubator.

Excised, inside-out patch-clamp recording. A single cation channel current was measured using an EPC-7 amplifier (List Electronics; Instrutech, Port Washington, NY) and the excised, inside-out patch-clamp method. Microelectrodes were pulled from $1.5 \mathrm{~mm}$ external diameter borosilicate glass capillaries (TW 150 F-4; World Precision Instruments, Sarasota, FL) and fire- polished to a resistance of 2-5 M $\Omega$ when filled with nASW (composition as above but lacking glucose, penicillin, and streptomycin). After excision, the cytoplasmic face was bathed with artificial intracellular saline composed of (in $\mathrm{mM}$ ): $500 \mathrm{~K}$-aspartate, 70 $\mathrm{KCl}, 0.77 \mathrm{CaCl}_{2}, 1.2 \mathrm{MgCl}_{2}, 10 \mathrm{HEPES}, 11$ glucose, 0.77 EGTA, and 10 glutathione; $\mathrm{pH}$ adjusted to 7.3 with $\mathrm{KOH}$; the calculated free $\left[\mathrm{Ca}^{2+}\right]$ was $\sim 1 \mu$ M. Regarding the calculated free $\left[\mathrm{Ca}^{2+}\right]$, we used salts of the highest purity grade [from J. T. Baker Chemical Company (Phillipsburg, NJ), Mallinckrodt (Hazelwood, MD), or Sigma (St. Louis, MO)], and care was taken to measure amounts of $\mathrm{CaCl}_{2}$ and EGTA accurately to ensure that the free $\left[\mathrm{Ca}^{2+}\right]$ was as close as possible to the calculated theoretical value (calculation performed with the CaBuffer program, courtesy of Dr. L. Schlichter, University of Toronto, Toronto, Canada). Data were acquired with an IBM-compatible personal computer, a Digidata 1200 analog-to-digital converter (Axon Instruments, Foster City, CA), and the Fetchex acquisition program pClamp (version 6.02; Axon Instruments). Current was filtered at $1 \mathrm{kHz}$ with a Bessel filter (Frequency Devices, Haverhill, MS) and sampled at $10 \mathrm{kHz}$. Data were gathered in 1-3 min intervals while holding the patch at $-60 \mathrm{mV}$ or, to avoid occasional contamination by $\mathrm{Ca}^{2+}$-activated $\mathrm{K}^{+}$currents, at -80 $\mathrm{mV}$.

Whole-cell current-clamp recording. Membrane potential responses to $\mathrm{CtVm}$ (see below) were measured with the EPC-7 amplifier and the tight-seal, whole-cell method. Microelectrodes (glass capillaries as above) were fire- polished to a resistance of 1-2 $\mathrm{M} \Omega$ when filled with artificial intracellular saline. [Composition was as described above, but $\mathrm{CaCl}_{2}$ was reduced to $0.595 \mathrm{~mm}$ for a calculated free $\left[\mathrm{Ca}^{2+}\right]$ of $\sim 300 \mathrm{nM}$ and supplemented with 5 mM ATP (grade 2, disodium salt; Sigma A3377) and $0.1 \mathrm{~mm}$ GTP (type 3, disodium salt; Sigma G8877)]. The $\sim 300 \mathrm{~nm}$ concentration of free intracellular $\mathrm{Ca}^{2+}$ is based on the fura-imaging and ion-sensitive electrode measurements of cytosolic $\mathrm{Ca}^{2+}$ concentrations in cultured bag cell neurons that were obtained by our and other laboratories (Fisher et al., 1994; Knox et al., 1996; Magoski et al., 2000). The extracellular solution was nASW (composition as initially described). In some cases, $50 \mu \mathrm{M} \mathrm{PKC}_{19-36}$ pseudosubstrate inhibitor peptide (Sigma P8462) or a $300 \mathrm{~nm}$ concentration of either src SH3 domain or yes SH3 domain was included in the intracellular saline. Data were acquired with the Clampex acquisition program of pClamp to either monitor membrane potential or inject current to measure input resistance. Voltage was taken from the EPC-7 V-reference and sampled at 1 $\mathrm{Hz}$ to monitor membrane potential or $2 \mathrm{kHz}$ for input resistance assessment. Measurements were made from $-50 \mathrm{mV}$, which was maintained as necessary by constant current injection from the EPC-7.

Reagents and drug application. Bacterially expressed, purified interaction domain fusion proteins and motif peptides were generous gifts from Dr. B. K. Kay (University of Wisconsin, Madison, WI). The original constructs were generated by amplifying predicted regions encoding the interaction domains by PCR, followed by subcloning into glutathione
$S$-transferase (GST) gene fusion vectors as described by Gee et al. (1998), Pirozzi et al. (1997), and Sparks et al. (1996). Motif peptides were synthesized as described by Pirozzi et al. (1997).

$\mathrm{CtVm}$ lyophilate was generously provided by Dr. B. M. Olivera (University of Utah, Salt Lake City, UT). Adult specimens of the molluscivorous snail $C$. textile were collected from the ocean around the island of Marinduque in the Philippines. Venom ducts were dissected out of an animal and placed on an ice- cold metal spatula. The duct was then cut into $2 \mathrm{~cm}$ sections and the venom was extruded by squeezing with forceps. The venom was then lyophilized in a vacuum centrifuge and stored at $-80^{\circ} \mathrm{C}$ for subsequent extraction. To prepare the crude $\mathrm{CtVm}$, procedures were performed at $4^{\circ} \mathrm{C}$, and the lyophilized venom was made up in $0.5 \%(\mathrm{v} / \mathrm{v})$ trifluoroacetic acid (TFA) for a final protein concentration of $5 \%(\mathrm{w} / \mathrm{v})$. The $\mathrm{CtVm}$ was vortexed for $2 \mathrm{~min}$ and sonicated for $2 \mathrm{~min}$, in an alternating manner, for a total of $18 \mathrm{~min}$. The mixture was then centrifuged at $15,000 \times g$ for $12 \mathrm{~min}$, and the supernatant was collected. A second aliquot of TFA was added to the pellet (final protein concentration of $10 \% \mathrm{w} / \mathrm{v})$, and the protocol was repeated. The supernatants were pooled, divided into aliquots, and frozen at $-80^{\circ} \mathrm{C}$.

$\mathrm{CtVm}$ and other drugs were introduced into the bath by pipetting a small volume $(<10 \mu \mathrm{l})$ of concentrated stock solution into the Petri dish ( $2 \mathrm{ml}$ volume). Care was taken to pipette the stock near the side of the dish and as far away as possible from the patch or neuron. $\mathrm{CtVm}$ was diluted to a final protein concentration of $\sim 100 \mu \mathrm{g} / \mathrm{ml}$. ATP (grade 2, disodium salt; Sigma A3377) was diluted to a final concentration of $1 \mathrm{~mm}$.

Analysis. To determine single- channel open probability $\left(P_{\mathrm{O}}\right)$ and make statistical descriptions of channel kinetics, event lists were made from single- channel data files by using the half-amplitude threshold criterion of the Fetchan analysis program of pClamp (Colquhoun and Sigworth, 1995). For analysis, most data did not require additional filtering below the $1 \mathrm{kHz}$ used during acquisition; however, to avoid inclusion of noise-related "events" as channel openings, some data were filtered a second time by using the Fetchan digital Gaussian filter to a final cutoff frequency of $500 \mathrm{~Hz}$. For display in figures, some data were filtered to a final cutoff frequency of 500 or $250 \mathrm{~Hz}$. The Pstat analysis program of pClamp was used to read events lists and determine the $P_{\mathrm{O}}$ for a given data file, either automatically or manually, but in both cases the following formula was used: $P_{\mathrm{O}}=\left(t_{1}+t_{2}+\ldots t_{\mathrm{n}}\right) / N \times t_{\text {tot }}$, where $t$ equals the amount of time that $n$ channels are open, $N$ equals the number of channels in the patch, and $t_{\text {tot }}$ equals the time interval over which $P_{\mathrm{O}}$ is measured. The number of channels in the patch was determined by counting the number of overlapping unitary current levels, particularly at more positive voltages (up to $-20 \mathrm{mV}$ ). Pstat was also used to generate single- channel open and closed dwell-time histograms and fit them with a sum of exponentials describing the kinetic behavior of the channel. The time interval ( $x$-axis) was binned logarithmically, and histograms were fit by using the maximum likelihood estimator method (Colquhoun and Sigworth, 1995) and a simplex search, which was given the number of exponential and estimated time constants $(\tau)$ at the start. Maximum likelihood fitting allowed comparisons between fits with different numbers of exponentials, typically by using the log likelihood ratio (LLR) of one model with a given number of one exponential versus another model with a larger number of exponentials. Models were considered not different if the LLR was $\leq 2$. Kinetic analysis was performed exclusively on patches that contained only one cation channel, as determined by a consistent display of only one open current level over several minutes, again at more positive voltages (up to $-20 \mathrm{mV}$ ).

The magnitude of the $\mathrm{CtVm}$-induced depolarization was taken as the difference between the pre- $\mathrm{CtVm}$ potential (maintained at $-50 \mathrm{mV}$ ) and the peak of the depolarization. If the $\mathrm{CtVm}$ elicited action potentials, the peak depolarization was measured at the potential just after the cessation of spiking. As an assay of neuronal viability, input resistance was measured with a steady-state response to a $10-50 \mathrm{pA}$ hyperpolarizing current injection and Ohm's law.

Data are presented as the mean and SEM. Statistical analysis was performed by using Instat (version 2.01; GraphPad Software Inc., San Diego, CA). Student's $t$ test was used to test for differences between two means. Data were considered significantly different at $p<0.05$.

\section{RESULTS}

\section{ATP enhances cation channel activity}

In the present study, cation channels were recorded using excised, inside-out patches from cultured Aplysia bag cell neurons. We have demonstrated previously that application of ATP to the 


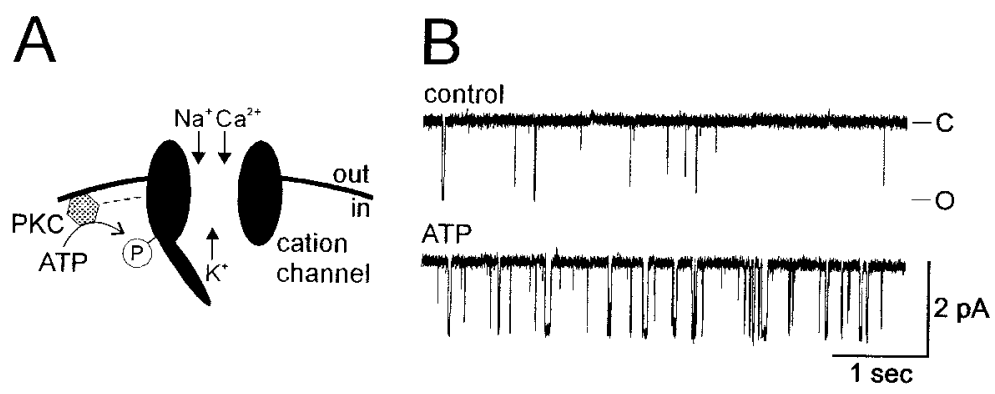

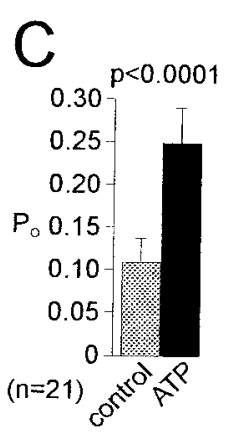

Figure 1. ATP increases cation channel $P_{\mathrm{O}}$ in excised, inside-out patches from cultured bag cell neurons. $A$, Model of the cation channel based on Wilson et al. (1998). Under physiological conditions, the channel passes $\mathrm{Na}^{+}, \mathrm{K}^{+}$, and $\mathrm{Ca}^{2+}$. ATP is used as a phosphate source in a phosphotransfer reaction catalyzed by a closely associated PKC-like enzyme $(P K C)$. This phosphorylation of either the cation channel itself or a nearby protein results in enhanced activity. The purpose of the present study was to examine the nature of the interaction between the cation channel and the kinase. B, Top trace, At a holding potential of $-60 \mathrm{mV}$, cation

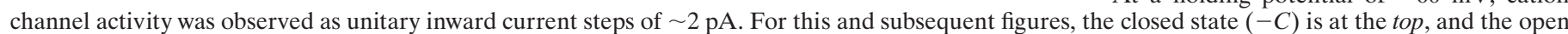

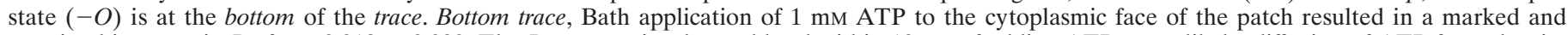

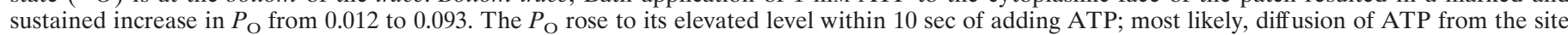

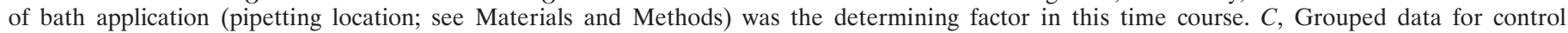

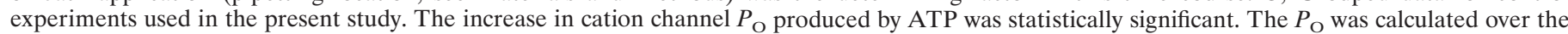

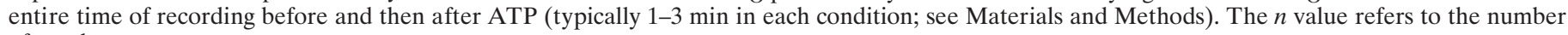
of patches.

cytoplasmic face of a patch containing a cation channel results in an increase in $P_{\mathrm{O}}$. This is attributable to the phosphorylation of the cation channel, or some adjacent protein, by a closely associated PKC-like enzyme (Fig. 1A) (Wilson et al., 1998). This channel-kinase association or "complex" can be defined in functional terms; i.e., because the regulation of the channel by PKC persists in excised patches, the kinase must be associated with the channel in some manner, although we cannot say whether this association is direct or not. Cation channels were readily identified on the basis of a conductance of $25-30 \mathrm{pS}(\sim 2 \mathrm{pA}$ inward current at $-60 \mathrm{mV}$ ), an increased $P_{\mathrm{O}}$ with depolarization, a lack of voltage-dependent inactivation, and a distinct kinetic profile of a three exponential component description for closed times and a two exponential component description for open times (Wilson and Kaczmarek, 1993; Wilson et al., 1996). When the cytoplasmic face of the patch was exposed to $1 \mathrm{mM} \mathrm{ATP}$, there was a rapid and sustained elevation of cation channel $P_{\mathrm{O}}$ lasting for the remainder of the recording period (up to $20 \mathrm{~min}$ ) (Fig. $1 B$ ). In experiments on 21 patches, performed as parallel controls throughout the present study, ATP produced an increase in cation channel $P_{\mathrm{O}}$ from a mean control value of $\sim 0.1$ to a mean final level of $\sim 0.25$ (Fig. 1C). Enhancement of activity occurred regardless of initial $P_{\mathrm{O}}$, although larger proportional increases were more often detected from lower starting $P_{\mathrm{O}}$ levels. For patches with channels showing an initial $P_{\mathrm{O}}$ of $<0.1$, the fold increase in $P_{\mathrm{O}}$ with ATP was $19.9 \pm 10.1(n=13)$, whereas for patches with channels whose initial $P_{\mathrm{O}}$ was $>0.1$, the fold increase was $1.7 \pm 0.2(n=8)$ (see also Wilson et al., 1998).

\section{Cation channel modulation is disrupted by src SH3 domain}

We sought to examine the nature of the association between the cation channel and the kinase by applying various protein-protein interaction domains and binding peptides to the cytoplasmic face as a means of disrupting the channel-kinase association and preventing the ATP response. We tested the potential role of SH3 domains in mediating the cation channel-kinase association by using GST fusion proteins of SH3 domains from several proteins. The most effective domain tested was the SH3 domain from src itself, which is part of one of the noncatalytic regions of the tyrosine kinase molecule (Koch et al., 1991). When the SH3 domain from src (amino acids 87-143; 60-100 nM) was applied to the cytoplasmic face of a cation channel-containing patch and then followed by ATP, the expected elevation of $P_{\mathrm{O}}$ failed to occur $(n=7)$ (Fig. $2 A, C)$. On its own, the src SH3 domain did not alter cation channel activity $(n=5)$ (Fig. $2 C)$. Interestingly, the ATP-induced increase in cation channel $P_{\mathrm{O}}$ was not affected by GST fusion proteins of SH3 domains from yes, a tyrosine kinase related to $\operatorname{src}(150-375 \mathrm{nM} ; n=4)$ (Fig. 2B, C, left traces), or grb2, a prototypical scaffolding protein, (N-terminal SH3 domain; 100$300 \mathrm{~nm} ; n=4)$ (Fig. 2B,C, right traces); in addition, these domains did not alter channel activity on their own (data not shown). This suggests that the inhibition of the ATP response by the src SH3 domain is attributable to a specific interaction between this domain and the channel-kinase complex and is not the result of some nonspecific effect of the domain storage buffer or the GST tag.

Another candidate interaction domain, and one that is found in scaffolding proteins known to organize complexes containing ionotropic glutamate receptors or certain $\mathrm{K}^{+}$channels, is the PSD-95, disks-large, ZO-1 (PDZ) domain (Kennedy, 1995; Sheng and Wyszynski, 1997; Staub and Rotin, 1997). Application of the GST-tagged PDZ domain of nitric oxide synthase (NOS) (130$250 \mathrm{~nm})$, however, had little impact on cation channel activity and did not prevent the ATP-induced increase in $P_{\mathrm{O}}(n=4)$ (Fig. $2 D, E)$. Similarly, a GST fusion protein of the PDZ domain from $\alpha_{1}$ - syntrophin (100 nM; $\left.n=1\right)$ did not alter baseline cation channel behavior or affect the ATP response (data not shown).

\section{Cation channel modulation is disrupted by src SH3 motif peptide}

SH3 domains bind to a motif with the consensus amino acid sequence $\mathbf{X}_{6} \mathbf{P X X P X}_{6}$ (Pawson and Scott, 1997), and the specificity of interactions with distinct SH3 domains is determined primarily by the variable residues that flank the invariant prolines (boldface type) (Sparks et al., 1996). The prolines are thought to interact with the domain at a core binding groove, whereas the overall specificity of the interaction is mediated by binding between the flanking peptide amino acids and an adjacent specificity pocket on the domain (Nguyen et al., 1998). We tested the effects of exposing the cytoplasmic face of cation channel-containing patches to a $1 \mu \mathrm{M}$ concentration of the src $\mathrm{SH} 3$ motif peptide $\left(\mathrm{NH}_{2}\right.$-LASRPLPLLPNSAPGQ-COOH; underlined residues are key for binding to the src form of the SH3 domain) (Sparks et al., 1996). The src SH3 motif peptide did not alter cation channel gating in the absence of ATP, and like the src SH3 domain, the peptide prevented the ATP-induced elevation of channel $P_{\mathrm{O}}(n=$ 
Figure 2. The ATP-induced increase in channel $P_{\mathrm{O}}$ is blocked by the src $\mathrm{SH} 3$ proteinprotein interaction domain. $A$, Application of a $100 \mathrm{~nm}$ concentration of the GST fusion protein of the SH3 domain from the tyrosine kinase src prevented the enhancement of cation channel $P_{\mathrm{O}}$ by ATP $(0.005$ in src SH3 vs 0.005 in src SH3 plus $1 \mathrm{~mm}$ ATP). The domain was bath-applied to the cytoplasmic face of the patch, which in this case contained two channels, and was followed by ATP $\sim 2$ min later. The patch was held at $-60 \mathrm{mV}$. B , The block is specific to the src form of the SH3 domain, because GST-fused SH3 domains from the related tyrosine kinase yes (left traces) $\left(P_{\mathrm{O}}=\right.$ 0.014 in $375 \mathrm{~nm}$ yes SH3 vs 0.116 in yes $\mathrm{SH} 3$ plus $1 \mathrm{~mm}$ ATP) or the $\mathrm{N}$-terminal SH3 domain from the grb2 adaptor protein (right traces; $P_{\mathrm{O}}=0.014$ in $300 \mathrm{~nm}$ grb2N SH3 vs 0.116 in grb2N SH3 plus $1 \mathrm{~mm}$ ATP) fail to inhibit the ATP-induced $P_{\mathrm{O}}$ increase. Both patches were held at $-60 \mathrm{mV}$. $C$, Summary data for the effect of SH3 domains on the cation channel response to ATP. The src SH3 domain had no effect itself on channel $P_{\mathrm{O}}$; furthermore, it prevented ATP from enhancing $P_{\mathrm{O}}$. This is in contrast to the SH3 domains from yes or grb2N, neither of which impeded the significant elevation of $P_{\mathrm{O}}$ by ATP. For $C$ and $E$, the $n$ values refer to the number of patches; n.s., Not significant. D, Exposure to the GST-fused PDZ interaction domain from the enzyme NOS did not prevent ATP from increasing cation channel $P_{\mathrm{O}}(0.208$ in 130 nM NOS PDZ vs 0.573 in NOS PDZ plus $1 \mathrm{~mm} \mathrm{ATP).} \mathrm{The} \mathrm{patch} \mathrm{was} \mathrm{held} \mathrm{at}-60 \mathrm{mV}$. E, Summary data for the effect of the NOS PDZ domain on cation channel activity and the ATP response. The PDZ domain did not alter cation channel activity, nor did it hinder ATP from significantly enhancing $P_{\mathrm{O}}$.

4) (Fig. 3A,D). If the domain in the channel-kinase complex that interacts with the src $\mathrm{SH} 3$ motif peptide is an src-like $\mathrm{SH} 3$ domain, then a peptide that binds an SH3 domain different from that of src should not block the ATP response. To examine this, a second $\mathrm{SH} 3$ motif peptide, one that preferentially binds the abl SH3 domain $\left(\mathrm{NH}_{2}\right.$-SGSGSRPPRWSPPVPLPTSLDSR-COOH; underlined residues are key for binding to the abl form of $\mathrm{SH} 3$ domain) (Sparks et al., 1996), was applied at $1 \mu \mathrm{M}$ to cation channel-containing patches. This second SH3 motif peptide did not alter cation channel behavior, nor did it disrupt the ability of ATP to increase channel $P_{\mathrm{O}}(n=4)$ (Fig. $\left.3 B, D\right)$. As a secondary control for the vehicle or any contaminating solvents used during peptide synthesis, we also tested the effects of a WW motif peptide $\left(\mathrm{NH}_{2}\right.$-LKLPDYWESSAS-COOH; $\left.1 \mu \mathrm{M}\right)$. Like the abl SH3 motif peptide, the WW motif peptide had no effect on cation channel activity or the ATP-induced increase in $P_{\mathrm{O}}(n=4)$ (Fig. $3 C, D)$.

The investigation of cation channel modulation by the closely associated PKC also described a phosphatase-like activity present in excised patches that reverses the PKC effect after withdrawal of ATP, returning $P_{\mathrm{O}}$ to control levels (Wilson et al., 1998). Therefore, we tested whether the ATP response could be reversed by applying src SH3 motif peptide after the addition of ATP; i.e., can disruption of the SH3-dependent channel-kinase association allow the phosphatase to act, despite a maintained presence of ATP? Figure $4 A$ shows an experiment in which the $P_{\mathrm{O}}$ of a very active, single cation channel (top trace) was markedly increased by the application of ATP to the cytoplasmic face of the patch (middle trace); subsequently, the addition of $1 \mu \mathrm{M}$ src SH3 motif peptide produced a shift of the $P_{\mathrm{O}}$ back toward control levels (bottom trace). The same experiment was also performed on two other patches, containing multiple channels with lower starting $P_{\mathrm{O}}$ levels, and resulted in an identical outcome $\left(P_{\mathrm{O}}=0.026 \pm\right.$
0.012 in controls vs $0.105 \pm 0.061$ in ATP vs $0.022 \pm 0.019$ in ATP plus src SH3 motif peptide). These experiments also indicate that the phosphatase remains activated and associated with the membrane patch in the presence of the competing peptide.

Because the patch from the experiment depicted in Figure $4 \mathrm{~A}$ contained only a single cation channel with a relatively high $P_{\mathrm{O}}$ (see Materials and Methods for information about determining the single- channel status of a patch), this allowed for kinetic analysis of the behavior of the channel and made it possible to separate the effect of dephosphorylation from any nonspecific effect of the src SH3 motif peptide. Under control conditions, cation channel closed times (Fig. 4B, top left graph) were best described by three exponentials (with time constants $\tau_{\mathrm{C} 1}, \tau_{\mathrm{C} 2}$, and $\tau_{\mathrm{C} 3}$ ), whereas the open times (Fig. $4 B$, top right graph) were best fit with a function consisting of two exponentials (with time constants $\tau_{\mathrm{O} 1}$ and $\tau_{\mathrm{O} 2}$ ). ATP application resulted in an obvious decrease in both the duration and relative contribution of $\tau_{\mathrm{C} 3}$ to the fitted function (Fig. 4B, middle left graph). At the same time, $\tau_{\mathrm{C} 1}$ and $\tau_{\mathrm{C} 2}$ underwent only slight changes, the exception being an increase in the number of events described by these time constants. With regard to open times in the presence of ATP, $\tau_{\mathrm{O} 1}$ and $\tau_{\mathrm{O} 2}$ showed only nominal changes in the number of events that they described (Fig. 4B, middle right graph). When the src $\mathrm{SH} 3$ motif peptide was applied after ATP, the duration and proportion of closures described by $\tau_{\mathrm{C} 3}$ reverted back to control values (Fig. $4 B$, bottom left graph). In addition, there was a return toward control levels for the relative contribution of $\tau_{\mathrm{O} 1}$ and $\tau_{\mathrm{O} 2}$ (Fig. $4 B$, bottom right graph). This reversal of the kinetic profile of the channel, combined with the lack of an effect in the absence of ATP, suggests that the src SH3 motif-induced return of $P_{\mathrm{O}}$ to control levels, in the presence of ATP, is most likely attributable to disruption of the channel-kinase complex and subsequent 


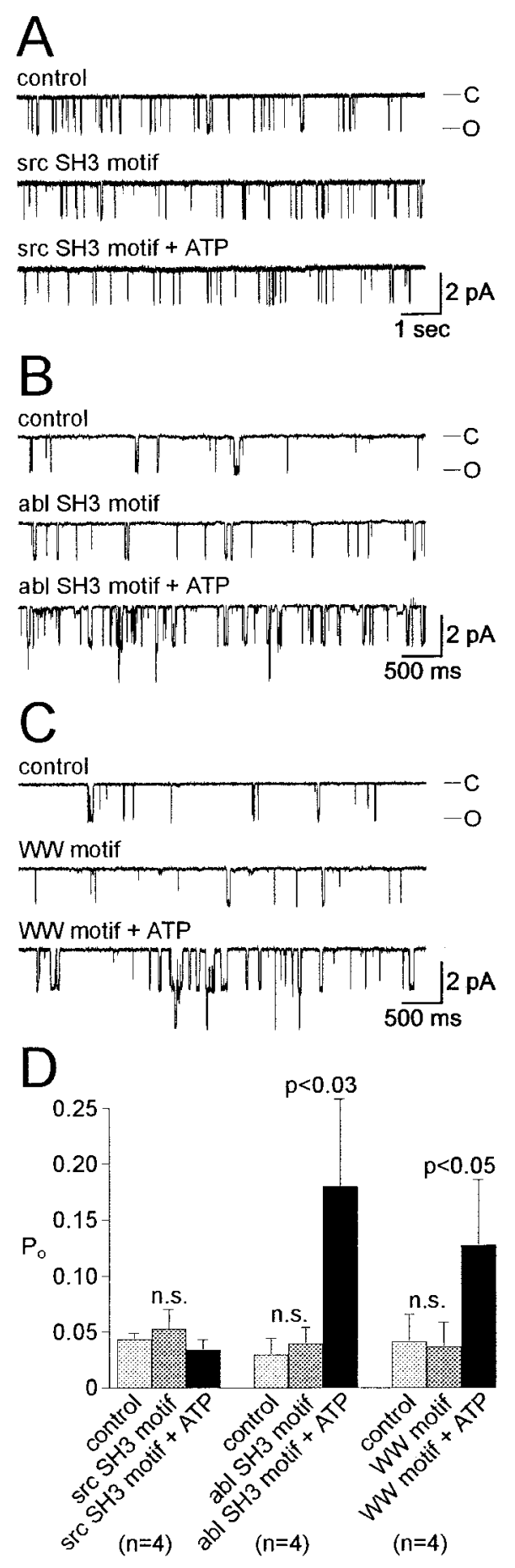

Figure 3. An src SH3 motif peptide blocks the ATP-induced increase in $P_{\mathrm{O}}$. $A$, In keeping with an SH3-like domain-mediated interaction being involved in the channel-kinase association, a $1 \mu \mathrm{M}$ concentration of an $\mathrm{SH} 3$ motif peptide $\left(\mathrm{NH}_{2}\right.$-LASRPLPLLPNSAPGQ-COOH, src SH3 motif) that preferentially binds to the src SH3 domain blocked the ATP response $\left(P_{\mathrm{O}}=0.038\right.$ in controls vs 0.037 in src SH3 peptide vs 0.025 in src SH3 peptide plus $1 \mathrm{~mm}$ ATP). The src SH3 motif peptide was in the bath for $\sim 2$ min before the addition of ATP. The patch was held at -60 $\mathrm{mV}$. $B$, To determine the specificity of the disruption of the channel-kinase complex by the src SH3 motif, a second $\mathrm{SH} 3$ motif $\left(\mathrm{NH}_{2}{ }^{-}\right.$ SGSGSRPPRWSPPVPLPTSLDSR-COOH, abl SH3 motif) was used that preferentially binds the abl SH3 domain over the src SH3 domain. A $1 \mu \mathrm{M}$ dose of abl SH3 motif peptide failed to block the ATP response $\left(P_{\mathrm{O}}=0.023\right.$ in controls vs 0.037 in abl SH3 peptide vs 0.073 in abl SH3 peptide plus $1 \mathrm{~mm}$ ATP). $C$, As an additional control for nonspecific effects, a $1 \mu \mathrm{M}$ phosphatase-dependent dephosphorylation, rather than an effect of the peptide on the channel itself.

We also applied a mixture of $100 \mathrm{~nm}$ src SH3 domain plus $1 \mu \mathrm{M}$ src SH3 motif peptide to excised patches and tested the effect on the response to $1 \mathrm{~mm}$ ATP. This domain/peptide mixture also blocked the ability of ATP to increase cation channel $P_{\mathrm{O}}(0.062 \pm$ 0.022 in domain/peptide vs $0.047 \pm 0.012$ in domain/peptide plus ATP; $n=3$; not significant; data not shown).

\section{Cation channel-mediated bag cell neuron depolarization is attenuated by PKC inhibition or src SH3 domain}

To address the role of the $\mathrm{SH} 3$ domain-mediated interactions in the regulation of bag cell neuron excitability, we used interaction domains to disrupt the channel-kinase complex during whole-cell recording of cation channel-mediated depolarization in cultured bag cell neurons. Cation channels can be reliably activated in cultured bag cell neurons by the extracellular application of a crude extract of $\mathrm{CtVm}$. Previous work suggests that $\mathrm{CtVm}$ activates cation channels and depolarizes bag cell neurons through the binding of a component(s), most likely peptidergic (Olivera et al., 1990), to a membrane receptor and initiation of both the production of second messengers and the activation of protein kinases (Wilson and Kaczmarek, 1993; Wilson et al., 1996, Magoski et al., 2000) (N. S. Magoski and L. K. Kaczmarek, unpublished observations). In many ways, the $\mathrm{CtVm}$ response of cultured bag cell neurons can be viewed as an in vitro analog of the afterdischarge itself.

In the present study, we first tested whether there was a contribution of the PKC pathway to the $\mathrm{CtVm}$-induced depolarization of cultured bag cell neurons. Whole-cell current-clamp recordings were made from individual bag cell neurons, and the depolarizing $\mathrm{CtVm}$ responses of neurons dialyzed with control intracellular saline were compared with those dialyzed with a 50 $\mu \mathrm{M}$ concentration of the specific pseudosubstrate PKC inhibitor peptide $\mathrm{PKC}_{19-36}$ (House and Kemp, 1987) (see Materials and Methods). As depicted in Figure 5, the depolarizing response is often multiphasic, perhaps because of the production of multiple second messengers after $\mathrm{CtVm}$ application (see above). Figure $5 A$ (top traces) shows that previous dialysis with $\mathrm{PKC}_{19-36}$ attenuated the $\mathrm{CtVm}$-induced depolarization by approximately onethird with respect to controls ( $n=4$ and 4$)$. We subsequently determined whether disruption of the channel-kinase complex with the src $\mathrm{SH} 3$ domain would affect the $\mathrm{CtVm}$ response. When bag cell neurons were dialyzed with a $300 \mathrm{~nm}$ concentration of src SH3 domain ( $n=7$ and 7 ) (Fig. $5 A$, middle traces), the depolarization evoked by $\mathrm{CtVm}$ was again attenuated. Moreover, this reduction in the $\mathrm{CtVm}$-induced depolarization did not appear to be attributable to the buffer or to a nonspecific effect of the domain itself, because dialysis with $300 \mathrm{~nm}$ yes $\mathrm{SH} 3$ domain did

\section{$\leftarrow$}

concentration of the WW motif peptide $\left(\mathrm{NH}_{2}\right.$-LKLPDYWESSAS$\mathrm{COOH})$ was applied to the cytoplasmic face of a cation channelcontaining patch. This peptide did not interfere with the ATP-induced increase in $P_{\mathrm{O}}(0.042$ in controls vs 0.036 in WW peptide vs 0.055 in WW peptide plus $1 \mathrm{~mm}$ ATP). $D$, Summary data for the effect of src SH3, abl SH3, and WW motif peptides on the cation channel response to ATP. Of the two SH3 motif peptides, neither had a significant impact on channel activity; however, the src SH3 motif peptide but not the abl SH3 motif peptide inhibited the ATP-induced $P_{\mathrm{O}}$ elevation. Furthermore, not only did the WW motif peptide have no effect on cation channel $P_{\mathrm{O}}$, it also failed to prevent an increase in $P_{\mathrm{O}}$ by ATP. The $n$ values refer to the number of patches; n.s., Not significant. 


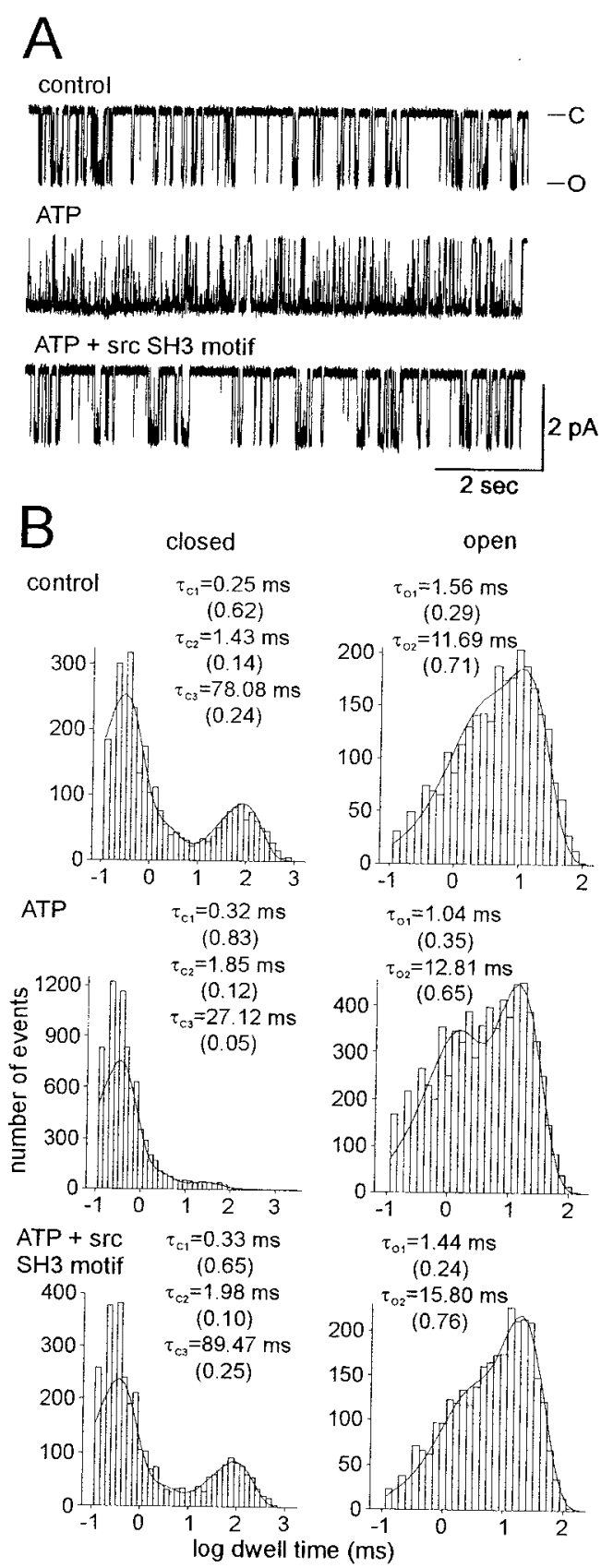

Figure 4. The src SH3 motif peptide reverses the ATP-induced increase in $P_{\mathrm{O}} . A$, A patch held at $-60 \mathrm{mV}$ displayed a single, rather active cation channel under control conditions $\left(P_{\mathrm{O}}=0.203\right)$. With the application of 1 mM ATP to the cytoplasmic face, the activity was markedly elevated $\left(P_{\mathrm{O}}=0.530\right)$. However, when $1 \mu \mathrm{M}$ SH3 motif peptide was added along with the ATP, the activity of the channel fell back toward control levels $\left(P_{\mathrm{O}}=0.316\right) . B$, Given that this patch appeared to contain only a single cation channel, kinetic analysis was possible. The histograms represent single- channel closed and open dwell times, fit with a sum of exponentials by using the maximum likelihood estimator method and a simplex search (see Materials and Methods). The time constants of the exponentials are given in the inset of each graph, with the proportion or fractional contribution to the area under the curve of each exponential shown in brackets under its respective time constant. During the control period (top graphs), cation channel closed times were best described by three exponentials $\left(\tau_{C 1}, \tau_{C 2}\right.$, and $\left.\tau_{C 3}\right)$ and the open times were best described by two exponentials $\left(\tau_{\mathrm{O} 1}\right.$ and $\left.\tau_{\mathrm{O} 2}\right)$. After exposure to ATP (middle graphs), the $\tau_{\mathrm{C} 1}$ or $\tau_{\mathrm{C} 2}$ showed little change; however, $\tau_{\mathrm{C} 3}$ was substantially reduced both in duration (a $65 \%$ decrease, from $\sim 78$ to $\sim 27 \mathrm{msec}$ ) and in the proportion of events that it described (a $80 \%$ decrease, from 0.25 to 0.05 ). not alter the peak depolarization compared with controls $(n=4$ and 4) (Fig. 5A, bottom traces). Finally, bag cell neuron input resistance, a simple assay of excitability, was unaffected by dialysis, regardless of the contents of the intracellular saline (Fig. 5C). The fact that the depolarization was inhibited to an equal extent by both the PKC inhibitor and the src SH3 domain suggests that, other than PKC, modulatory components involved in eliciting the depolarization were unaffected by the src SH3 domain.

\section{DISCUSSION}

Previous work has shown that much of the depolarizing drive and membrane potential instability of the afterdischarge originates from the activation of a defined cation conductance in the bag cell neurons (Kaczmarek and Strumwasser, 1984; Wilson and Kaczmarek, 1993; Wilson et al., 1996). The macroscopic as well as the underlying single-channel properties of this cation conductance are one of a slow, nonselective, $\mathrm{Ca}^{2+}$-permeable, $\mathrm{Ca}^{2+}$-sensitive, voltage-dependent, noninactivating current (Wilson et al., 1996; Magoski et al., 2000). Similar currents have been described in a number of molluscan and mammalian neurons, in which they contribute to bursting and repetitive firing (Wilson and Wachtel, 1974; Green and Gillette, 1983; Stafstrom et al., 1985; Swandulla and Lux, 1985; Alonso and Llinas, 1989). The afterdischarge is associated with changes in both the electrical and biochemical properties of the bag cell neurons (Conn and Kaczmarek, 1989). The activity of PKC, an enzyme that mediates several afterdischarge-associated biophysical changes (Strong et al., 1987; Knox et al., 1992), increases with onset of the afterdischarge (Wayne et al., 1999). With the same assay of excised, inside-out patches that was used in the present study, Wilson et al. (1998) showed that cation channel $P_{\mathrm{O}}$ is enhanced by the application of ATP, through the activity of a closely associated PKC-like enzyme. Thus, the increase in PKC activity is temporally consistent with the ability of the kinase to modulate cation channel behavior and suggests that this mechanism contributes to the electrical changes of the afterdischarge. The association of the cation channel with PKC is likely to promote cation channel modulation after a stimulus for initiating the afterdischarge.

We have now shown that application of either the SH3 domain from src or an src SH3 motif peptide (i.e., an optimized binding site for src SH3 domains) prevents the ATP-induced increase in cation channel $P_{\mathrm{O}}$. This inhibition probably reflects a disruption of the protein complex containing the channel and the kinase. The effects of the src SH3 domain and peptide were specific, because $\mathrm{SH} 3$ or PDZ domains from other proteins, as well as different motif peptides, did not inhibit the $P_{\mathrm{O}}$ increase elicited by ATP.

There are probably two ways in which the cation channel and the kinase could be closely associated in excised patches. First, the channel and kinase could be directly bound to each other, or second, an intermediary scaffolding protein could bind both channel and kinase, thereby bringing the two molecules together. Moreover, the substrate of PKC need not be the channel itself but could be another component of the complex. The idea of a scaffolding protein is somewhat more attractive, given the number of components that potentially make up the signaling com-

\section{$\leftarrow$}

For open times during ATP, there was a modest shift, from $\tau_{\mathrm{O} 2}$ to $\tau_{\mathrm{O} 1}$, in the proportion of events described. After application of the $\mathrm{SH} 3$ motif peptide (bottom graphs), $\tau_{\mathrm{C} 3}$ values returned to near control levels. Similarly, the number of events described by $\tau_{\mathrm{O} 1}$ and $\tau_{\mathrm{O} 2}$ shifted back toward control levels. 

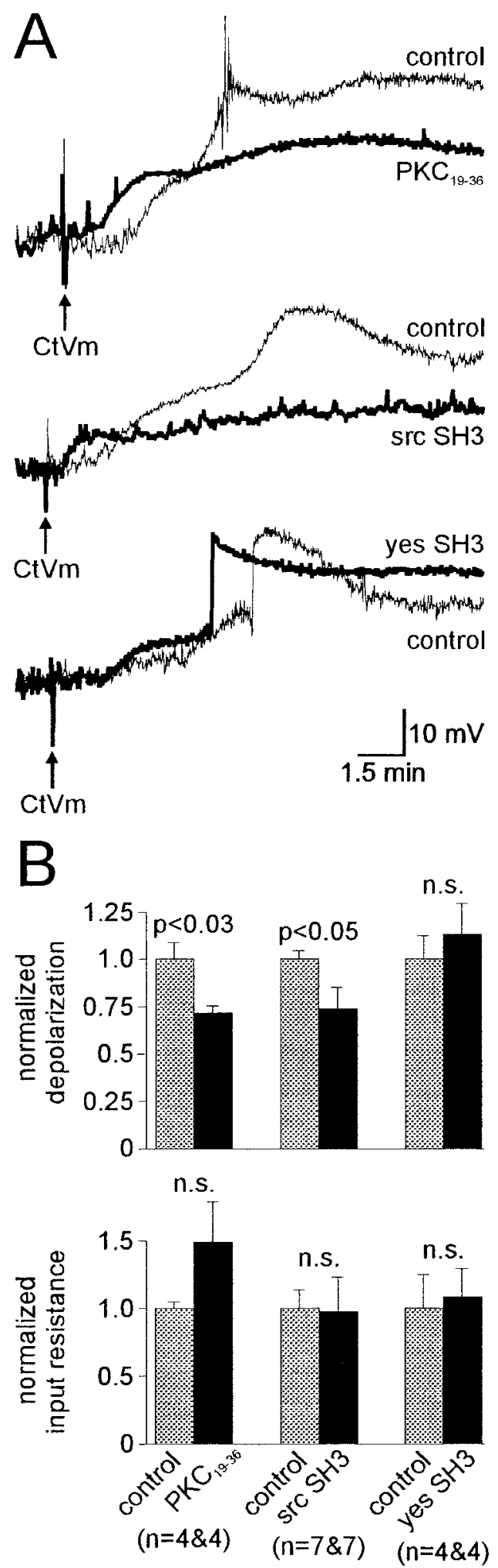

Figure 5. $\mathrm{CtVm}$-induced depolarization is reduced by both a PKC inhibitor and the src SH3 domain. $A$, Whole-cell current-clamp recordings of depolarizations elicited by $\mathrm{CtVm}(100 \mu \mathrm{g} / \mathrm{ml})$ in cultured bag cell neurons. $\mathrm{CtVm}$ responses in neurons dialyzed with control intracellular saline ( gray line) are displayed along with responses of neurons dialyzed with intracellular saline containing $50 \mu \mathrm{M} \mathrm{PKC}_{19-36}, 300 \mathrm{nM}$ src SH3 domain, or $300 \mathrm{~nm}$ yes SH3 domain (black line). Neurons were dialyzed for $45 \mathrm{~min}$ before $\mathrm{CtVm}$ bath application (arrow). The peak $\mathrm{CtVm}$ - plex. Along with the PKC activity, two phosphatase activities are also present in excised, inside-out patches, namely, a serinethreonine phosphatase that is capable of reversing the effects of PKC and a tyrosine phosphatase that is activated by exogenous protein kinase A (PKA) (Wilson and Kaczmarek, 1993; Wilson et al., 1998). Furthermore, recent work suggests that a $\mathrm{Ca}^{2+}$ - sensing mechanism involved in production of the refractory period into which the bag cell neurons enter after an afterdischarge may also be closely tethered to the cation channel (Magoski et al., 2000). The scaffolding protein hypothesis is also supported by the fact that the two PKC isoforms that have been cloned so far from Aplysia nervous tissue do not have apparent SH3 domains (Kruger et al., 1991). However, these data do not preclude the possibility that the channel itself may contain the SH3 domain, whereas the enzyme possesses an undefined binding motif.

There appears to be a high degree of specificity for both the src form of the SH3 domain and the src SH3 motif peptide over other $\mathrm{SH} 3$ domains and peptides in preventing the ATP response. This specificity may represent the possibility that src tyrosine kinase, in addition to its catalytic properties, also plays a scaffolding role in the cation channel-kinase protein complex. For example, Seibenhener et al. (1999) demonstrated that an atypical PKC isoform, $\mathrm{PKC} \zeta$, binds to $\mathrm{v}$-src tyrosine kinase. The role of src tyrosine kinase in the regulation of the cation channel is as yet unknown, however, although our preliminary attempts suggest that src tyrosine kinase inhibits $P_{\mathrm{O}}$ in the presence of ATP (Magoski and Kaczmarek, unpublished observation). Furthermore, we cannot completely exclude the possibility that the apparent specificity of the src SH3 domain represents its structural similarity to a native scaffolding protein.

There are examples of both direct and scaffolded enzymechannel interactions. Src tyrosine kinase has been shown to closely associate with NMDA receptors (Yu et al., 1997) and Kv1.5 $\mathrm{K}^{+}$channels (Holmes et al., 1996). Moreover, the srcKv1.5 association was shown to be mediated by the direct interaction of the src SH3 domain and a polyproline $\mathrm{SH} 3$ motif on the $\mathrm{K}^{+}$channel (Holmes et al., 1996). A well- studied example of a scaffolding protein is the multi-PDZ domain protein known as inaD (inactivation no-after potential D), which serves to assemble

\footnotetext{
$\leftarrow$

induced depolarization for neurons dialyzed with either $\mathrm{PKC}_{19-36}$ (top traces) or src SH3 domain (middle traces) was reduced compared with controls; however, dialysis with yes SH3 domain (bottom traces) did not have a obvious impact on the peak depolarization. The control $\mathrm{CtVm}$ response depicted in the top traces shows some action potentials approximately halfway through the recording period; the spikes are truncated because of the low digitization rate and the display scale. Differences in the onset of the depolarization are not significant and are most likely attributable to experimental variability. $B$, Summary data for the effect of $\mathrm{PKC}_{19-36}$, src SH3 domain, or yes SH3 domain on the bag cell neuron membrane potential response to $\mathrm{CtVm}$ and on input resistance before $\mathrm{CtVm}$ application. Top graph, On average, both $\mathrm{PKC}_{19-36}$ and src $\mathrm{SH} 3$ domain dialysis significantly reduced the depolarization by approximately one-third compared with controls. The SH3 domain from yes did not produce any significant change in the $\mathrm{CtVm}$-induced depolarization. Bottom graph, Input resistance (see Materials and Methods) was measured at the end of dialysis and just before the application of $\mathrm{CtVm}$. Compared with controls, none of the agents introduced into the neurons had a significant effect on input resistance. The apparent but nonsignificant elevation after $\mathrm{PKC}_{19-36}$ introduction was attributable to a single neuron showing an inexplicable increase in input resistance over the dialysis period. The labels apply to both the top and bottom graphs, and the $n$ values refer to the number of control and experimental neurons examined in a given set. n.s., Not significant.
} 
a signal transduction complex of phospholipase C, PKC, and the trp channel in Drosophila photoreceptors (Tsunoda et al., 1997; Tsunoda and Zuker, 1999). Another, more wide spread set of scaffolding proteins are cAMP-dependent protein kinaseanchoring proteins (AKAPs), some of which bring together several different phosphatases and kinases (Coghlan et al., 1995; Klauck et al., 1996). Peptide interference techniques similar to those used in the present study suggest that AKAPs participate in the PKA-dependent modulation of ionotropic glutamate receptors, $\mathrm{Ca}^{2+}$ channels, and $\mathrm{Na}^{+}$channels, presumably by linking these channels with the kinase (Rosenmund et al., 1994; Johnson et al., 1997; Cantrell et al., 2000).

We also examined the potential role of the PKC-induced modulation of the cation channel in whole-cell recordings from isolated bag cell neurons. Cation channels were activated in cultured bag cell neurons by extracellular application of $\mathrm{CtVm}$. The depolarizing response to $\mathrm{CtVm}$ in cultured bag cell neurons is attributable to activation of the cation channel and can be considered an in vitro analog of the afterdischarge itself (Wilson and Kaczmarek, 1993; Wilson et al., 1996; Magoski et al., 2000). We first sought to establish whether the CtVm-induced depolarization has a component that is dependent on PKC activation. The specific PKC pseudosubstrate inhibitor $\mathrm{PKC}_{19-36}$ (House and Kemp, 1987), which has been shown previously to be very effective in preventing the increase in cation channel $P_{\mathrm{O}}$ elicited by ATP (Wilson et al., 1998), reduced the CtVm-induced depolarization by approximately one-third compared with controls. This level of reduction in response amplitude is in keeping with the fact that other pathways, including PKA, may be turned on by $\mathrm{CtVm}$ and contribute to cation channel activation and subsequent depolarization. There are data indicating that the cAMP/PKA pathway initiates a number of changes in bag cell neuron excitability during the afterdischarge (Kaczmarek et al., 1978, 1980; Kaczmarek and Strumwasser, 1981, 1984). Similarly, the CtVminduced activation of the cation channel in cultured bag cell neurons involves, at least in part, a PKA-regulated pathway (Wilson and Kaczmarek, 1993). Thus, both the PKA and PKC pathways appear to act on the cation channel to enhance its activity and promote depolarization.

The $\mathrm{CtVm}$ response of cultured bag cell neurons was also attenuated by approximately one-third after dialysis with the SH3 domain from src but not the domain from yes. This suggests that, as in excised patches, modulation of the cation channel, as assayed by $\mathrm{CtVm}$-induced depolarization, may involve $\mathrm{SH} 3$ domainmediated protein-protein interactions. It should be noted that if additional enzymatic components of the signaling complex had also been affected by the src SH3 domain, it is likely that the inhibition of the $\mathrm{CtVm}$-induced depolarization would have been larger than that observed with the PKC inhibitor. Overall, the results indicate not only that modulation of the cation channel requires specific protein-protein interactions, namely $\mathrm{SH}$-like interactions, to orchestrate channel modulation by $\mathrm{PKC}$, but also that these interactions may play a part in cation channel-mediated depolarization of bag cell neurons. It would appear that signaling complexes are a common means by which ion channel modulation is carried out. This is supported by reports from the literature of regulatory enzymes being linked to ion channels (Holmes et al., 1996; Tsunoda et al., 1997; Yu et al., 1997; Tibbs et al., 1998; Davare et al., 2001) or of kinase modulation of ion channels persisting in cell-free system conditions (Rehm et al., 1989; Chung et al., 1991; Bielefeldt and Jackson, 1994; Yu et al., 1997; Wilson et al., 1998). For the bag cell neurons, it may very well be that a number of different protein-protein interactions are required to network the second messengers and enzymes that regulate their activation and initiation of the afterdischarge.

\section{REFERENCES}

Alonso A, Llinas RR (1989) Subthreshold $\mathrm{Na}^{+}$-dependent theta-like rhythmicity in stellate cells of entorhinal cortex layer II. Nature 342:175-177.

Bielefeldt K, Jackson MB (1994) Phosphorylation and dephosphorylation modulate a $\mathrm{Ca}^{2+}$-activated $\mathrm{K}^{+}$channel in rat peptidergic nerve terminals. J Physiol (Lond) 475:241-254.

Cantrell AR, Tibbs VC, Westenbrock RE, Scheuer T, Catterall WA (2000) Dopaminergic modulation of voltage-gated $\mathrm{Na}^{+}$current in rat hippocampal neurons requires anchoring of cAMP-dependent protein kinase. J Neurosci 19:RC21:1-6.

Chung S, Reinhart PH, Martin BL, Brautigan D, Levitan IB (1991) Protein kinase activity closely associated with a reconstituted calciumactivated potassium channel. Science 253:560-562.

Coghlan VM, Perrino BA, Howard M, Langeberg LK, Hicks JB, Gallatin WM, Scott JD (1995) Association of protein kinase A and protein phosphatase 2B with a common anchoring protein. Science 267:108-111.

Cohen GB, Ren R, Baltimore D (1995) Modular binding domains in signal transduction proteins. Cell 80:237-248.

Colquhoun D, Sigworth FJ (1995) Fitting and statistical analysis of single-channel records. In: Single channel recording (Sakmann B, Neher E, eds), pp 483-587. New York: Plenum.

Conn PJ, Kaczmarek LK (1989) The bag cell neurons of Aplysia. Mol Neurobiol 3:237-273.

Davare MA, Avdonin V, Hall DD, Peden EM, Burette A, Weinberg RJ, Horne MC, Hoshi T, Hell JW (2001) A $\beta_{2}$ adrenergic receptor signalling complex assembled with the $\mathrm{Ca}^{2+}$ channel $\mathrm{Ca}_{\mathrm{V}} 1.2$. Science 293:98-101.

Fanning AS, Anderson JM (1999) Protein modules as organizers of membrane structure. Curr Opin Cell Biol 11:432-439.

Fisher T, Levy S, Kaczmarek LK (1994) Transient changes in intracellular calcium associated with a prolonged increase in excitability in neurons of Aplysia californica. J Neurophysiol 71:1254-1257.

Gee SH, Sekely SA, Lombardo C, Kurakin A, Froehner SC, Kay BK (1998) Cyclic peptides as non-carboxyl-terminal ligands of syntrophin PDZ domains. J Biol Chem 273:21980-21987.

Green DJ, Gillette R (1983) Patch- and voltage-clamp analysis of cyclic AMP-stimulated inward current underlying neurone bursting. Nature 306:784-785

Holmes TC, Fadool DA, Ren R, Levitan IB (1996) Association of Src tyrosine kinase with a human potassium channel mediated by SH3 domain. Nature 274:2089-2091.

House C, Kemp BE (1987) Protein kinase C contains a pseudosubstrate prototope in its regulatory domain. Science 238:1726-1728.

Johnson BD, Brousal JP, Peterson BZ, Gallombardo PA, Hockerman GH, Lai Y, Scheuer T, Catterall WA (1997) Modulation of the cloned skeletal muscle L-type $\mathrm{Ca}^{2+}$ channel by anchored cAMP-dependent protein kinase. J Neurosci 17:1243-1255.

Kaczmarek LK, Strumwasser F (1981) The expression of long lasting afterdischarge by isolated Aplysia bag cell neurons. J Neurosci 1:626-634.

Kaczmarek LK, Strumwasser F (1984) A voltage-clamp analysis of currents underlying cyclic AMP-induced membrane modulation in isolated peptidergic neurons of Aplysia. J Neurophysiol 52:340-349.

Kaczmarek LK, Jennings K, Strumwasser F (1978) Neurotransmitter modulation, phosphodiesterase inhibitor effects, and cyclic AMP correlates of afterdischarge in peptidergic neurites. Proc Natl Acad Sci USA 75:5200-5204.

Kaczmarek LK, Jennings KR, Strumwasser F, Nairn AC, Walter U, Wilson FD, Greengard P (1980) Microinjection of catalytic subunit of cyclic AMP-dependent protein kinase enhances calcium action potentials of bag cell neurons in cell culture. Proc Natl Acad Sci USA 77:7487-7491

Kennedy MB (1995) Origin of PDZ (DHR, GLGF) domains. Trends Biochem Sci 20:350.

Klauck TM, Faux MC, Labudda K, Langeberg LK, Jaken S, Scott JD (1996) Coordination of three signalling enzymes by AKAP79, a mammalian scaffold protein. Science 271:1589-1592.

Knox RJ, Quattrocki EA, Connor JA, Kaczmarek LK (1992) Recruitment of $\mathrm{Ca}^{2+}$ channels by protein kinase $\mathrm{C}$ during rapid formation of putative neuropeptide release sites in isolated Aplysia neurons. Neuron 8:883-889.

Knox RJ, Jonas EA, Kao L-S, Smith PJS, Connor JA, Kaczmarek LK (1996) $\mathrm{Ca}^{2+}$ influx and activation of a cation current are coupled to intracellular $\mathrm{Ca}^{2+}$ release in peptidergic neurons of Aplysia californica. J Physiol (Lond) $494: 627-693$.

Koch CA, Anderson D, Moran MF, Ellis C, Pawson T (1991) SH2 and 
SH3 domains: elements that control interactions of cytoplasmic signalling proteins. Science 252:68-674.

Kruger KE, Sossin WS, Sacktor TC, Bergold PJ, Beushausen S, Schwartz $\mathrm{JH}$ (1991) Cloning and characterization of $\mathrm{Ca}^{2+}$-dependent and $\mathrm{Ca}^{2+}$-independent PKCs expressed in Aplysia sensory cells. J Neurosci 11:2303-2313.

Kupfermann I (1967) Stimulation of egg laying: possible neuroendocrine function of bag cells of abdominal ganglion of Aplysia californica. Nature 216:814-815.

Kupfermann I, Kandel ER (1970) Electrophysiological properties and functional interconnections of two symmetrical neurosecretory clusters (bag cells) in abdominal ganglion of Aplysia. J Neurophysiol 33:865-876.

Levitan IB, Kaczmarek LK (1997) The neuron: cell and molecular biology. New York: Oxford UP.

Magoski NS, Knox RJ, Kaczmarek LK (2000) Activation of a $\mathrm{Ca}^{2+}$ permeable cation channel produces a prolonged attenuation of intracellular $\mathrm{Ca}^{2+}$ release in Aplysia bag cell neurones. J Physiol (Lond) 522 :271-283.

Nguyen JT, Turck CW, Cohen FE, Zuckermann RN, Lim WA (1998) Exploiting the basis of proline recognition by $\mathrm{SH} 3$ and $\mathrm{WW}$ domains: design of N-substituted inhibitors. Science 282:2088-2092.

Olivera BM, River J, Clark C, Ramilo CA, Corpuz GP, Abogadie FC, Mena EE, Woodward SR, Hillyard DR, Cruz LJ (1990) Diversity of Conus neuropeptides. Science 249:257-263.

Pawson T (1995) Protein modules and signalling networks. Nature 373:573-579.

Pawson T, Scott JD (1997) Signalling through scaffold, anchoring, and adaptor proteins. Science 278:2075-2080.

Pinsker HM, Dudek FE (1977) Bag cell control of egg laying in freely behaving Aplysia. Science 197:490-493.

Pirozzi G, McConnell SJ, Uveges AJ, Carter JM, Sparks AB, Kay BK, Fowlkes DM (1997) Identification of novel human WW domaincontaining proteins by cloning of ligand targets. J Biol Chem 272:14611-14616.

Rehm H, Pelzer S, Cochet C, Chambaz E, Tempel BL, Trautwein W, Pelzer D, Lazdunski M (1989) Dendrotoxin-binding brain membrane protein displays a $\mathrm{K}^{+}$channel activity that is stimulated by both cAMP-dependent and endogenous phosphorylations. Biochemistry 28:6455-6460.

Rosenmund C, Carr DW, Bergeson SE, Nilaver G, Scott JD, Westbrook GL (1994) Anchoring of protein kinase A is required for modulation of AMPA/kainate receptors on hippocampal neurons. Nature 368:853-856.

Rothman BS, Weir G, Dudek FE (1983) Egg-laying hormone: direct action on the ovotestis of Aplysia. Gen Comp Endocrinol 52:134-141.

Seibenhener ML, Roehm J, White WO, Neidigh KB, Vandenplas ML, Wooten MW (1999) Identification of src as a novel atypical protein kinase C-interacting protein. Mol Cell Biol Res Commun 2:28-31.
Sheng M, Wyszynski M (1997) Ion channel targeting in neurons. BioEssays 19:847-853.

Sparks AB, Rider JE, Hoffman NG, Fowlkes DM, Quillan LA, Kay BK (1996) Distinct ligand preferences of src homology 3 domains from src, yes, ab1, cortactin, p53bp2, PLCgamma, crk, and grb2. Proc Natl Acad Sci USA 93:1540-1544.

Stafstrom CE, Schwindt PC, Chubb MC, Crill WE (1985) Properties of persistent sodium conductance and calcium conductance of layer $\mathrm{V}$ neurons from cat sensorimotor cortex in vitro. J Neurophysiol 53:153-170.

Staub O, Rotin D (1997) Regulation of ion transport by protein-protein interaction domains. Curr Opin Nephrol Hypertens 6:447-454.

Strong JA, Fox AP, Tsien RW, Kaczmarek LK (1987) Stimulation of protein kinase $\mathrm{C}$ recruits covert calcium channels in Aplysia bag cell neurons. Nature 325:714-717.

Swandulla D, Lux HD (1985) Activation of a nonspecific cation conductance by intracellular $\mathrm{Ca}^{2+}$ elevation in bursting pacemaker neurons of Helix pomatia. J Neurophysiol 54:1430-1443.

Tibbs VC, Gray PC, Catterall WA, Murphy BJ (1998) AKAP15 anchors cAMP-dependent protein kinase to brain sodium channels. J Biol Chem 273:25783-25788.

Tsunoda S, Zuker CS (1999) The organization of INAD-signalling complexes by a multivalent PDZ domain protein in Drosophila photoreceptor cells ensures sensitivity and speed of signalling. Cell Calcium 26:165-171.

Tsunoda S, Sierralta J, Sun Y, Bodner R, Suzuki E, Becker A, Socolich M, Zuker CS (1997) A multivalent PDZ-domain protein assembles signalling complexes in a G-protein-coupled cascade. Nature 388:243-249.

Wayne NL, Lee W, Kim YJ (1999) Persistent activation of calciumactivated and calcium-independent protein kinase $\mathrm{C}$ in response to electrical afterdischarge from peptidergic neurons of Aplysia. Brain Res 834:211-213.

Wilson GF, Kaczmarek LK (1993) Mode-switching of a voltage-gated cation channel is mediated by a protein kinase A-regulated tyrosine phosphatase. Nature 366:433-438.

Wilson GF, Richardson FC, Fisher TE, Olivera BM, Kaczmarek LK (1996) Identification and characterization of a $\mathrm{Ca}^{2+}$-sensitive nonspecific cation channel underlying prolonged repetitive firing in Aplysia neurons. J Neurosci 16:3661-3671.

Wilson GF, Magoski NS, Kaczmarek LK (1998) Modulation of a calcium-sensitive nonspecific cation channel by ATP via a closelyassociated protein kinase. Proc Natl Acad Sci USA 95:10938-10943.

Wilson WA, Wachtel H (1974) Negative resistance characteristic essential for the maintenance of slow oscillations in bursting neurons. Science 186:932-934.

Yu X-M, Askalan R, Keil GJ, Salter MW (1997) NMDA channel regulation by channel-associated protein tyrosine kinase src. Science 275: $674-678$. 